\title{
MOTIVAÇÃO PARA A DOCÊNCIA E PRINCÍPIOS NORTEADORES DA PRÁTICA PEDAGÓGICA NOS ANOS FINAIS DO ENSINO FUNDAMENTAL: sentidos de professores
}

\author{
Isamary Roberta Ferreira Cézarl \\ Nilma Margarida de Castro Crusoé2
}

\begin{abstract}
RESUMO
Este artigo objetiva apresentar resultados da pesquisa sobre prática pedagógica, mais especificamente, sobre os motivos que os levaram a tornarem-se professores, bem como os sentidos que atribuem aos elementos que compõem à sua prática, nos anos finais do ensino fundamental. A Fenomenologia de Alfred Schutz (2012) é a base teórico-metodológica que sustenta e ampara este trabalho. Para a produção e análise dos dados utilizou-se da entrevista semiestruturada e da Análise de Conteúdo. Sobre a motivação para a docência, tem-se os seguintes resultados: memórias da infância, projeções quanto à possibilidade de exercício futuro da profissão e o gosto por ensinar desenvolvido por meio da prática de ensinar. Acerca dos elementos que compõem a prática pedagógica, os professores conceituam educação, escola, currículo e prática pedagógica numa perspectiva relacional. Os sentidos atribuídos à educação transcendem o universo escolar, é compreendida como ação social e constitui-se um processo que envolve toda a vida, com isso anunciam, que entendem a escola como um espaço-tempo de interação social e cultural, motivado pelo enredamento da prática pedagógica. A perspectiva de currículo nos discursos revela desde uma compreensão tradicional à visão crítica. Entende-se que na perspectiva da fenomenologia sociológica, tais sentidos atravessam a prática realizada pelos professores, nessa escola. Outro aspecto importante, os resultados obtidos na pesquisa permitem perspectivar a prática pedagógica com base na experiência intersubjetiva.
\end{abstract}

Palavras-chave: Prática Pedagógica. Ensino Fundamental. Sentidos.

\footnotetext{
1 Mestra em Educação, UESB - Brasil; Programa de Pós-graduação em Educação UESB Bahia; Membro do Grupo de Estudos e Pesquisa em Práticas Curriculares e Educativas (GEPPCE). Orcid iD: https://orcid.org/0000-0002-0610-8237. E-mail: isamaryrobertaferreira@gmail.com.br

2 Doutora em Educação, UFRN, com estágio doutoral na Universidade de Coimbra, PT; Professora Titular, Universidade Estadual do Sudoeste da Bahia (UESB); Professora do Programa de Pós-graduação em Educação (PPGEd); Líder do Grupo de Estudos e Pesquisa em Práticas Curriculares e Educativas (GEPPCE), CNPq. Orcid iD: https://orcid.org/0000-00020610-8237. E-mail: nilcrusoe@gmail.com.br
} 


\title{
MOTIVATION FOR TEACHING AND GUIDING PRINCIPLES OF PEDAGOGICAL
}

\section{PRACTICE IN THE FINAL YEARS OF ELEMENTARY SCHOOL: teachers' meanings}

\begin{abstract}
The purpose of this article is to present the results of the research on pedagogical practice, specifically, on the reasons that led them to become teachers, as well as the meanings they attribute to the elements that make up their practice, in the last years of elementary school. Alfred Schutz's Phenomenology (2012) is the theoreticalmethodological basis that supports this work. Semi-structured interviews and Content Analysis were used for data production and analysis. As for the motivation for teaching, the following results are found: childhood memories, projections about the possibility of future practice in the profession and the taste for teaching developed through the practice of teaching. Regarding the elements that make up pedagogical practice, teachers conceptualize education, school, curriculum, and pedagogical practice in a relational perspective. The meanings attributed to education transcend the school universe, it is understood as a social action and constitutes a process that involves all of life, thus announcing that they understand the school as a space-time of social and cultural interaction, motivated by the interweaving of pedagogical practice. The perspective of the curriculum in the discourses reveals from a traditional understanding to a critical vision by showing that the curriculum is developed through school knowledge. It is understood that from the perspective of sociological phenomenology, such meanings permeate the practice carried out by teachers in this school. Another important aspect, the results obtained in the research allow us to look at the pedagogical practice from the intersubjective experience.
\end{abstract}

Keywords: Pedagogical Practice. Elementary School. Meanings.

\section{MOTIVACIÓN PARA LA ENSEÑANZA Y PRINCIPIOS RECTORES DE LA PRÁCTICA PEDAGÓGICA EN LOS ÚLTIMOS AÑOS DE LA ENSEÑANZA PRIMARIA:}

\author{
significados de los profesores
}

\section{RESUMEN}

Este artículo objetiva presentar los resultados de la investigación sobre la práctica pedagógica, específicamente, sobre las razones que los llevaron a convertirse en docentes, así como los significados que atribuyen a los elementos que componen su práctica, en los últimos años de la escuela primaria. La Fenomenología de Alfred Schutz (2012) es la base teórico-metodológica que sustenta este trabajo. Para la producción y análisis de datos se utilizaron entrevistas semiestructuradas y Análisis de Contenido. En cuanto a la motivación para la docencia, se encuentran los siguientes resultados: memorias de la infancia, proyecciones sobre la posibilidad de la práctica futura en la profesión y el gusto por la docencia desarrollado a través de la práctica de la docencia. En cuanto a los elementos que componen la práctica pedagógica, los docentes conceptualizan la educación, la escuela, el currículo y la práctica pedagógica en una perspectiva relacional. Los significados atribuidos a la educación trascienden el universo escolar, se entiende como una acción social y 
constituye un proceso que involucra a toda la vida, así anuncian que entienden la escuela como un espacio-tiempo de interacción social y cultural, motivado por el entrelazamiento de la práctica pedagógica. La perspectiva curricular en los discursos revela desde una comprensión tradicional a una visión crítica. Se entiende que desde la perspectiva de la fenomenología sociológica, tales significados impregnan la práctica que realizan los docentes de esta escuela. Otro aspecto importante, los resultados obtenidos en la investigación nos permiten mirar la práctica pedagógica a partir de la experiencia intersubjetiva.

Palabras clave: Práctica Pedagógica. Escuela Primaria. Significados.

\section{INTRODUÇÃO}

Como resultado de uma pesquisa de mestrado 3 , que se interessou em ouvir o que os professores tem a dizer acerca das práticas pedagógicas que desenvolvem, este artigo trata sobre os motivos que os levaram a se tornarem professores e os princípios que norteiam suas práticas pedagógicas,-compreendida aqui como produtoras de sentidos compartilhados pelo grupo, que compõe a escola.

Sentido, nesta pesquisa, é tratado como sentido subjetivo atribuído por professores à sua ação, ou seja, a ação pedagógica é dotada de sentidos que ao serem revelados, via pesquisa, permitem perspectivar diferentes configurações de práticas ainda que ali se incluam prescrições governamentais. Isso nos provocou posicionar esta pesquisa na fenomenologia sociológica de Alfred Schutz (2012), por se tratar de um estudo que analisa os fenômenos do ser no contexto de suas interações sociais.

Nessa perspectiva, o mundo da escola e o mundo social são espaços que compõem a vida de indivíduos e cujo

[...] O mundo da vida constitui a esfera de todas as experiências, orientações e ações cotidianas, mediante as quais os indivíduos buscam realizar seus interesses e seus negócios a partir da manipulação de objetos, da interação

\footnotetext{
3 Pesquisa de mestrado desenvolvida junto ao Programa de Pós-Graduação em Educação (PPGEd), da Universidade Estadual do Sudoeste da Bahia (UESB). CÉZAR, Isamary Roberta Ferreira. Práticas pedagógicas nos anos finais do ensino fundamental: sentidos de professoras. Orientadora: Dra. Nilma Margarida de Castro Crusoé. Dissertação (mestrado) Universidade Estadual do Sudoeste da Bahia, Programa de Pós-Graduação em Educação PPGED, Vitória da Conquista, 2021.
} 
com as pessoas, da elaboração de planos e da efetivação destes (SCHUTZ, 2012, p.25).

O que nos consente estabelecer uma relação entre esses dois mundos. Isso refere-se ao constructo das interações sociais, sendo modificados a partir de processos interpretativos utilizados pelas pessoas ao lidarem com as questões encontradas.

Desse modo, o conhecimento escolar é entendido em sua amplitude envolve conhecimentos e valores dentro e fora do seu espaço/tempo - e, o processo de ensino, para além da dimensão pedagógica, engloba, as dimensões política, cultural e social, o que envolve considerá-los como aspectos da subjetividade que constituem elementos significativos e permitem que os indivíduos se organizem em sua vida prática e atribuam sentidos.

Isso, porque importa para esta pesquisa, conhecer a história das(o) informantes e suas experiências formativas, quais são seus motivos para ser professor(a), e como definem educação, escola, currículo, conhecimento escolar e prática pedagógica; conceitos que permeiam o dia a dia do docente. Nos interessa ouvir sobre como enxergam as relações entremeadas pelo contexto escolar, entender essa realidade implica escutar acerca das crenças, valores e atitudes (CRUSOÉ, 2014) que permeiam o fazer docente, e, portanto, que sentidos atribuem à prática pedagógica desenvolvida na escola, nos anos finais do ensino fundamental. Como afirma a professora Vogel (2020, p.18) "é a simplicidade que emoldura a memória emocional, que nos constitui como gente e, para reativá-la ao nível de consciência, é necessário nos perguntar: pelo que o nosso coração "suspira"?"

Para esse estudo, escolhemos a abordagem qualitativa por incidir sobre o universo de significados, motivos, aspirações, crenças, valores e atitudes, "[...] é de se desejar que as relações sociais possam ser analisadas em seus aspectos mais concretos e aprofundadas em seus significados mais essenciais" (MINAYO, 2001, p. 21-22). Entender a pesquisa de natureza qualitativa como um caminho para a compreensão dos processos sociais, históricos e, sobretudo, subjetivos, implica reconhecer a relevância da 
rigorosidade metódica dos pormenores, das questões macrossociais e a proposta desta pesquisa é desenvolver estudos com base em sentidos/significados do fazer pedagógico.

Com o objetivo de compreender o fenômeno e não elucidar as causas, a pesquisa qualitativa parte do princípio que é necessário investigar o específico e, isso é possível por meio do contato direto e interativo do pesquisador com o informante/objeto de estudo, o que justifica a escolha da entrevista semiestruturada como instrumento para conhecer e contextualizar o fenômeno, traduzindo e anunciando os sentidos atribuídos ao mundo social, segundo a perspectiva dos informantes. E da Análise de Conteúdo, com o objetivo de descrever a estrutura da experiência vivida e os significados que ela possui para os sujeitos que a vivenciam, embasados pela fenomenologia social, descrevemos as unidades de sentidos dos indivíduos por acessar o fluxo próprio da consciência, em sua natureza particular.

Os informantes desta pesquisa são quatro professoras e um professor do $6^{\circ}$ e $9^{\circ}$ anos do ensino fundamental, anos finais, que trabalham numa escola municipal no interior da Bahia, na região do sudoeste baiano, com menor índice de estudantes em distorção idade/série, nesse segmento escolar, segundo os dados do censo escolar 2018 (INEP, 2019) identificados no relatório de Trajetórias do Sucesso Escolar (UNICEF, 2018).

A escolha dos anos finais do ensino fundamental para o estudo se justifica por serem periodo de transição para o ensino médio. A escola escolhida tem o menor índice de reprovação e abandono em comparação com os dados gerais da cidade (BRASIL, 2018).

$\mathrm{Na}$ conversa com os informantes, foram construídos os alicerces para esta análise, as narrativas das professoras e do professor se tecem às experiências e recordações por elas/ele vividas, vem à memória acontecimentos, lugares e pessoas, são também evocadas expectativas, frustações, sonhos, que entre outros, nos levam a tempos e espaços diversos e diferentes, especialmente, o percurso trilhado em suas trajetórias. 
Ao ler este texto, desejamos que se perceba envolto num movimento constante que aproxima e distancia o passado e o presente, interligando-os, numa busca pela realidade. Isso permitirá compreender os contextos da prática profissional desenvolvido, por cada docente, e os sentidos que a ela atribuem.

\section{DE QUE PROFESSORES ESTAMOS FALANDO? SUAS MOTIVAÇÕES E EXPERIÊNCIAS FORMATIVAS}

Essa categoria nos permitiu acessar as motivações iniciais dos informantes no caminho para a tomada de decisão profissional em tornar-se professor(a). Descreve experiências de vida que decorrem em aprendizados, acompanham a sua trajetória pessoal e profissional, bem como sua prática docente e constituem os sentidos. Nesta seção, conversaremos sobre as razões que sustentam essa escolha e as experiências formativas que amparam a continuidade da trajetória.

Sobre as motivações para ser professora, Ester informa, a motivação maior para mim [...]. Eu [...] acredito na educação com esse pilar de transformação ${ }^{4}$. É importante destacar, em termos de método, que Ester antes da resposta acima afirmou sobre tal motivação que: a motivação maior para mim parece romântico né? ((risos)) E/ eu ((risos) Depois de vinte anos já de sala de aula e eu ainda ter essa visão, mas de fato, é o que eu acredito. Esse destaque aponta para a ideia de suspensão do mundo da vida e de reflexão proposta por Schutz (2012), ela reflete sobre o que diz, para então dizer.

Como discutido na metodologia, a professora "pensa sobre o próprio pensamento", ou seja, suspende o mundo da vida da escola para pensar sobre suas motivações para ser professora e aprendizagens formativas (CÉZAR; CRUSOÉ, 2021). Ester, considera pilares importantes a familia, a igreja, mas a educação (escolar) ela tem esse papel, diante dessa descrição, ela reconhece a existência de outros contextos formativos o que coaduna com

\footnotetext{
${ }_{4}$ Optamos por colocar a fala dos entrevistados em itálico para diferenciar da citação dos
} teóricos. 
a ideia schutziana de outros 'eus' que são a família, igreja (SCHUTZ, 2012; CRUSOÉ; SANTOS, 2020).

Maria, professora de Língua Portuguesa, como Ester, nos traz em sua narrativa uma memória, revela que quando criança brincava de todas as profissões, mas [...] gostava de ser a professora, distribuía todas as minhas tarefas sobre a cama, eu tinha uma vontade de trabalhar com isso. Maria, então, guiada pelas brincadeiras da infância, e na influência da relação com o outro, diante da experiência escolar. Ela pode fazer o magistério e cursos adicionais, prestou o concurso e aprovada, apresentou-se ao Estado para trabalhar [...] quando a gente chega no estado, naquela época, eles dão as piores turmas, a brincadeira ao imitar a professora sinaliza o sentimento de admiração que constitui o imaginário infantil como algo prazeroso, mas o encontro do mundo da vida com a consciência, segundo Schutz (2012), revela a realidade [...] eu levei um susto [...] acostumada com a prática da escola particular, professores, mas comprometidos e tal, e no estado não, todo mundo bem relaxadão.

É possível apreender, na análise das entrevistas apresentadas até aqui, que a vontade do ser professor está intrínseca à experiência de vida na relação com o outro. Dentro desse processo, uma projeção quanto à possibilidade para seguir a carreira se constitui como uma inclinação pessoal. O sentido se apresenta, portanto, com base em uma construção afetiva que permeia a intenção de contribuir para a transformação e solidifica uma inclinação pessoal do tornar-se professor e professora.

Ana e Rute, licenciadas em matemática, foram se tornando professoras, pois não tinham esse objetivo antes de adentrarem à escola. Ana descreve que [...] não queria ser professora, mas, para ter o Diploma de Ensino Superior, cursava a licenciatura de Matemática, por não serem as atividades de estágio optativas, ela foi encaminhada para a sala de aula, e assume que, [...] quando eu fui para o estágio obrigatório, eu me apaixonei, [...] foi amor mesmo, na prática. [...] na prática que eu me vi feliz com o que eu estava fazendo, me realizei, assim. 
Rute, compartilha de uma experiência semelhante, de forma segura ela afirma [...] na verdade, eu não queria dar aula. Para concluir o Ensino Médio, ela precisava escolher um curso, por ser moradora de cidade pequena, onde não havia opções e a família não ter condições financeiras de sustentá-la estudando em uma cidade maior, Rute fez [...] o magistério. Nos conta, entre risos, quando se casou [...] coincidiu de sair o concurso [...] fiz o concurso torcendo pra não passar, e mesmo aprovada no concurso acredito que uns cinco anos mais ou menos, eu resistir a sala de aula. [...] depois fui entrando pra escola, fui trabalhar na secretaria da escola.

As experiências formativas fazem parte da trajetória pessoal e social do indivíduo, são a base da formação, como nos revela Maria [...] aprendi muito nos cursos, [...] has próprias aulas e com os colegas [...], e Rute corrobora, [...] de lá pra cá, eu fui aperfeiçoando [...] fui fazer o curso de matemática. [...] E aí veio o gosto. O sentido ampara a constituição afetiva com base na experiência escolar, ou seja, na relação com o outro o sentimento do ser professora se sustenta de forma significativa. [...] fui entrando para a escola, pisando, firmando nesse chão. [...] Hoje eu já não me vejo fora duma sala de aula (RUTE, 2020).

O fazer docente para estas professoras, traduzido nas narrativas, tem uma relação significativa com aprender a gostar de dar aula (TOLEDO; COUTINHO, 2020). O sentido de gostar do trabalho que exercem, como uma experiência assinalada por satisfação pela profissão, construído no decorrer dos anos e ressignificado na constituição do sentido de ser professora. Sobre esse aspecto afirma Fontana (2000, p. 180, grifos do autor):

No tempo, vivemos e somos nossas relações sociais, produzimo-nos em nossa história. Falas, desejos, movimentos, formas perdidas na memória. No tempo nos constituímos, relembramos, repetimo-nos e nos transformamos, capitulamos e resistimos, mediados pelo outro, mediados pelas práticas e significados de nossa cultura. No tempo, vivemos o sofrimento e a desestabilização, as perdas, a alegria e a desilusão. Nesse moto contínuo, nesse jogo inquieto, está em constituição nosso "ser profissional". 
A aprendizagem e o trabalho docente são compreendidos nesses discursos em relação contínua com o trabalho do professor na escola, assim, "[...] o saber profissional se dá na confluência de vários saberes oriundos da sociedade, da instituição escolar, dos outros atores educacionais, das universidades, etc." (TARDIF, 2002, p. 19).

De acordo com Crusoé (2014, p. 70), "há entre as professoras uma ligação funcional que não é dada a priori, mas construída no contexto da rede de sentidos atribuídos nas relações e interações sociais", e acrescenta "ao mergulhar na vida, as professoras atribuem sentidos, e estes são rasurados pelos sentidos dos outros" (CRUSOÉ, 2015, p. 68). A análise realizada com base nos relatos de Ana e Rute, permite-nos compreender que, alicerçadas no percurso das experiências de vida, a motivação inicial se torna fundamental, porque é essência para o entendimento de como cada professor concebe a sua prática pedagógica, ou seja, por meio de quais experiências elas significam. Como afirma Crusoé (2014, p. 68),

A realidade é refletida e refratada, ao mesmo tempo, e interpretada de forma múltipla e heterogênea. Nesse processo, as professoras tornam-se autoras e criadoras das suas histórias de ser professora, porque a realidade passa pelo crivo das interpretações e posições valorativas.

Desse modo, a singularidade ampara a subjetividade das decisões tomadas durante sua trajetória, pois se ancora na importância ofertada pelo sujeito mesmo influenciadas em suas experiências formativas na relação com o outro. Contudo, ao analisar os discursos, fica claro que os sentidos que traduzem a motivação inicial para se tornar professor perpassam aspectos como memórias da infância, projeções quanto à possibilidade de exercício futuro da profissão e o gosto por ensinar desenvolvido por meio da prática.

Concebemos que os sentidos atribuídos à prática pedagógica, pelas(os) professoras(es), podem ser entendidos com base na ideia de Schutz (2012), segundo o qual o indivíduo, desde seu nascimento, constitui-se em um mundo compartilhado por relações interpessoais, estrutura-se mediante experiências diárias e comuns, cuja "[...] realidade é como algo 
criado pelo homem a partir de suas experiências intersubjetivas [...]" (SCHUTZ, 2012, p. 59). Isto é, a realidade é construída e significada nas relações intersubjetivas, percebidas e interpretadas de várias formas. Por isso, os diferentes modos de olhar e observar a realidade nos interessam, pois são fundamentais para esse trabalho.

Portanto, os sentidos analisados são permeados e se constroem na relação com o outro, despertam a motivação e estruturam lembranças afetivas ao longo da formação pessoal de modo significativo - no caso das análises realizadas por este trabalho - a intenção de ingressar na profissão docente desponta na experiência de vida ligada à expectativa, à observação, às condições possíveis, à admiração e ao afeto. Tais aspectos, em um dado momento, revelam as inclinações pessoais para abraçar a carreira profissional, fortalecendo o modo como aprende e desenvolve a prática pedagógica.

\section{SENTIDOS DOS PROFESSORES: PRINCÍPIOS NORTEADORES DA SUA PRÁTICA PEDAGÓGICA}

Essa categoria revela alguns aspectos do pensamento dos informantes que, de acordo com o método adotado nesta pesquisa, interfere na sua ação pedagógica. O objetivo nesta seção é apresentar sentidos dos professores, em uma perspectiva de princípios orientadores da prática pedagógica. A conversa foi organizada por intermédio das compreensões acerca do conceito de educação, uma vez que, ao partir das narrativas dos professores, as falas se associam à escola, ao currículo e a outras questões pertinentes à prática pedagógica, guiando, inclusive, os próprios sentidos atribuídos em relação aos outros conceitos aqui apresentados.

Trata-se, de conhecer o que pensam os entrevistados sobre educação, currículo e escola. A análise dos discursos desenvolvida aqui, descreve de que forma os conhecimentos e a ação inspiram a prática pedagógica das professoras. Diante disso, três subcategorias puderam ser constituídas em função dos relatos: a educação - em relação ao seu papel formativo na sociedade; currículo - e suas implicações na prática, diante 
das necessidades do estudante; e escola - como espaço de construção do conhecimento.

\subsection{A educação em relação ao seu papel formativo na sociedade}

Nas palavras de Ester, educação como essa maneira que o cidadão tem de mudar sua vida, de crescer, de ser uma pessoa mais atenta, mais aberta para o mundo, acerca disso, Manoel observa que a educação é sempre uma prática no tempo e no espaço, como tudo que a gente faz; enquanto para Maria, a educação é isso tudo, que não aprende só na escola, faz parte da família, da sociedade o educar o ser humano. Aos discursos citados pode-se inferir que para os professores entrevistados, a educação está associada à compreensão em sua concepção ampliada, tanto ao se referir aos espaços onde ocorre quanto às diferentes formalidades a ela atribuídas. Notem! Maria, entende que a educação é responsabilidade de um todo social. Manoel, aponta a educação no âmbito da formação constitutiva humana e tem relação com o modo de agir dos sujeitos. Ester, concebe-a como pilar da cidadania. Isto é, eles compreendem a educação como um elemento que extrapola a dimensão do aprender na escola e está na base da formação cidadã.

Os sentidos atribuídos à educação, pelas informantes, são como uma arena, abertos, nas palavras de Amado (2017, p. 27),

[...] onde as dimensões éticas, política, científica, experiencial, emocional e afetiva terão, forçosamente, que se articular de um ponto de vista prático para a realização plena de cada um, de cada pessoa, e do universo dos seres humanos.

Estaria assim, a educação, associada a um papel mais alargado, no que tange a que conhecimento é este que se ensina e como ele é ensinado.

Nos termos de Manoel, [...] o problema não está no conhecimento científico [...] está em como [...] articula esses conhecimentos para que se tornem [...] pertinentes. Desse modo, o professor define que educação é um 
processo de práxis. É uma teoria que informa a prática e a prática precisa ser analisada para informar a teoria. Para tanto, é preciso ter definido a concepção de gente, nas palavras de Maria, se você não tem uma concepção de homem, que seja humana [...] você acaba não sabendo para quê [...] ou para quem você tá trabalhando. Esse entendimento se aproxima da perspectiva defendida pela tendência progressista - crítico social dos conteúdos e a pedagogia histórica-crítica, quanto a essência da escola: difusão de conhecimento científico, numa abordagem que vivifica os conteúdos e assegura a indissociabilidade das realidades sociais, porque reconhece o sujeito em sua inteireza, e entende que [...] a educação é algo necessário, [...] é o meio de transformar mesmo o cidadão (ENTREVISTADA MARIA, 2020).

Educação, ainda no entendimento de Ester, é como mola propulsora ali para a formação da pessoa humana, [...] educação enquanto essa possibilidade de fazer com que esse cidadão cresça. Então, [...] intrínseca mesmo na formação do ser humano, tem o papel de não criar aquela pessoa individualista. Maria corrobora com essa compreensão ao dizer que tem a questão também de transformar e lapidar mesmo o ser humano, desenvolvendo o potencial da pessoa, [...] já tem a inteligência, tem as vontades, mas a educação ainda é o meio de humanizar o homem. Enquanto Ana ressalta, que educação trata [...] não só de conteúdo, mas de valores e Rute nos lembra sobre [...] aquela educação que não depende da escola, ela reflete na escola, [...] a educação familiar [...] da sociedade. As falas das professoras movimentam essa discussão por apresentar um sentido de educação que tem como princípio a formação do indivíduo, realçam o desenvolvimento dos estudantes como projeção social e reconhecem se este processo constituído de modo relacional.

Cada sociedade precisa cuidar da formação dos indivíduos, auxiliar no desenvolvimento de suas capacidades físicas e espirituais, prepará-los para a participação ativa e transformadora nas várias instancias da vida social. A prática educativa não é apenas uma exigência da vida em sociedade, mas também o processo de prover os indivíduos 
dos conhecimentos e experiências culturais que os tornam aptos a atuar no meio social e a transformá-los em função de necessidades econômicas, sociais e políticas da coletividade (LIBÂNEO, 1994, p. 17).

Nessa concepção de educação faz parte uma educação escolar que oferte as condições necessárias para a formação dos estudantes, de forma a contribuir efetivamente para uma melhor construção social, política e econômica.

O sentido de educação abordado nas unidades de registro acima, apresenta a perspectiva de que a educação escolar, tratada como conhecimento, carece instruir, por meio do processo de ensino e aprendizagem, para colaborar na transformação de vida das pessoas, da realidade dos estudantes. Concordamos com o entendimento embasado na perspectiva educacional, que compreende o processo como uma prática social que tem a intencionalidade de ensinar e formar criticamente. Dessa maneira, a educação escolar "socializa o saber sistematizado e desenvolve capacidades cognitivas e operativas para a atuação no trabalho e nas lutas sociais pela conquista dos direitos de cidadania" (LIBÂNEO, 1994, p. 33).

\section{2 o currículo e suas implicações na prática}

Então currículo é escola, é o movimento, é o que acontece dentro da escola [...] tudo que acontece ali, você tá ensinando o menino. Escolhemos continuar a conversa acerca do pensamento do professor com essa fala de Rute, pois nos apresenta um sentido de currículo na perspectiva da instrução, ou seja, comporá o currículo se ensinar algo. Amplia essa perspectiva quando afirma que [...] o currículo não é só isso. Você recebe um currículo formal que vem, [...] de cima para baixo que você vai ter que trabalhar, mas esse currículo é transformado pelo professor.

Segundo Maria, currículo [...] é o que você pensa é [...] o currículo de vida que você passa para o aluno [...] da sua vivência, do seu compreender o mundo [...] vai além do que tá ali formalizado. Ester comunga com essa 
ideia quando diz que cabe [...] à prática pedagógica adequar o currículo à necessidade dele (do estudante). Esse é olhar que o professor deve ter (ESTER, 2020, grifos nossos) e continua, um currículo ideal para atender às necessidades do aluno tem haver com um currículo que fale da sua realidade, que ele se reconheça nesse currículo. A relevância desse entendimento, na prática se dá, segundo Ester, porque o aluno ainda não tá, ou não teve... as habilidades necessárias para pegar aquilo que o currículo na série dele apresenta. Por isso, Rute insiste que, mesmo recebendo formalmente as diretrizes sobre o que e quando ensinar, o professor o transforma. Afinal você [...] prepara uma aula [...] quando você chega em sala de aula, você muda a aula completamente dependendo do que tiver acontecendo.

O sentido de currículo que assenta nas falas, sustenta-se em uma visão crítica ao descrever que o conhecimento escolar parte da relação entre o ensinar e o aprender do estudante enquanto participante do processo. A proposta, nessa compreensão, é articular o conhecimento escolar com uma perspectiva de currículo que intenciona a contextualização da aprendizagem.

O conceito de currículo, em face dos diversos significados que 0 enreda - poder, ideologias, valores e crenças - é um conceito complexo a ser constituído. Está associado à própria identidade da instituição escolar, ao seu aparelhamento, à sua organização, funcionamento, disposição e ao papel que exerce, fatalmente, como uma bússola acerca do que, quando e porque ensinar. Pode ser acentuado como prática de poder, discursiva, significação e de atribuição de sentidos. O conhecimento e a cultura são partes inerentes do poder, dos processos de dominação e dos processos de significação. O currículo, portanto, constrói a realidade, dirige, obriga, delineia a nossa identidade, produzindo sentidos (LOPES, 2011, p. 41).

Nesse contexto, os informantes revelam "[...] o entendimento de currículo como prática de significação, como criação ou enunciação de sentidos [...]" (LOPES, 2011, p. 42). De modo que a escolarização tem por 
função oferecer um projeto educativo significativo que intenciona lidar com aspectos escolares diversos e que se modificam de escola e para a escola.

Importa frisar que o conhecimento escolar, como alicerce para transmitir $\circ$ que se decidiu para $\circ$ aprendizado dos alunos, segue um percurso selecionado por meio do currículo, organizado em conteúdos didáticos escolhidos por órgão institucionalizado e burocrático. Além disso, no contexto escolar, nem sempre é estruturado por profissionais de educação.

O currículo indicado pelo sistema educacional interfere na estruturação do conhecimento que será discutido e socializado. Por isso, para compreender a constituição do currículo, vale discutir sobre a organização do currículo, a contribuição de Apple (2006) quando aborda a matriz curricular proposta. O planejamento centrado em componentes curriculares é o ponto de partida da maior parte das escolas, configura-se como conhecimento curricular referencial, sendo que a maior razão

[...] para que os currículos centrados nas disciplinas dominem a maior parte das escolas, e para que os currículos integrados estejam presentes em relativamente poucas escolas, é, pelo menos, parcialmente, o resultado do lugar da escola na maximização da produção de conhecimento de alto status. Isso está intimamente relacionado com o papel da escola na seleção de agentes para preencher posições econômicas e sociais em uma sociedade relativamente estratificada que os analistas da economia política da educação têm tentado retratar (APPLE, 2006, p. 73).

Entender o currículo de modo real e dinâmico é importante, pois assim, compreende que ele carece de ajustamentos e adequações, diante do processo de ensino e aprendizagem, comprometido e com significado. Segundo Sacristán (2000, p. 15), "quando definimos currículo, estamos descrevendo as concretizações das funções da própria escola e a forma particular de enfocá-las num momento histórico e social determinado para um nível de modalidade de educação, numa trama institucional".

Por isso, Rute inicia sua resposta à pergunta da entrevista, por dizer, quando a gente fala em currículo, a gente pensa logo em conteúdo [...] e 
Maria, descreve o currículo como esse hall de conteúdos e disciplinas, [...] um currículo físico das disciplinas, não há como negar, a perspectiva tradicional do currículo que é essa concepção como uma forma de organização que intenciona guiar o trabalho pedagógico e transmitir um conteúdo. Isso é perceptível a preocupação de Manoel, quando aborda que a gente (escola) está há tempo demais focando em passar no vestibular, em atender ao mercado e não nos preocupamos com a formação humana (MANOEL, 2020, grifos nossos).

Os sentidos traduzidos por essas falas evidenciam abranger 0 conhecimento escolar como inerentes ao professor e à função docente (ensinar). Essa abordagem acerca do saber dos professores é afiançada na imagem social de que esse conhecimento decorre de uma pluridimensionalidade do "saber profissional" docente. Ela é referendada por Tardif (2002), para quem "[...] o saber docente é um saber composto de vários saberes oriundos de fontes diferentes e produzidos em contextos institucionais e profissionais variados" (TARDIF, 2002, p. 11). Dessa forma, os saberes experienciais são gerados em face de vivências, de sua caminhada dentro e fora do ambiente escolar, em um eterno vir a ser (SCHUTZ, 2012, p. 32).

\subsection{A escola como espaço de construção do conhecimento}

A escola é: (1) [...] local que é o ambiente do saber [...] cantinho reservado, com pessoas orientando; para Maria. Enquanto que para Rute, define como (2) um espaço onde as pessoas que ali estão, os profissionais [...] buscam [...] contribuir para a formação [...] de quem vai à escola. É compreendida por Ana como (3) um ambiente propício para uma pessoa [...] ensinar e aprender ao mesmo tempo, [...] é um lugar para... ensino e aprendizagem mesmo. Ester, apreende-o como (4) espaço acadêmico para viabilizar o conhecimento mesmo, a construção de conhecimento [...] Escola pra mim, enquanto esse espaço não fechado. Manoel entende que (5) [...] a escola é palco de tudo que acontece em nossa sociedade. Ela não é uma bolha fechada onde ela se idealiza e se realiza de forma ideal. 
A conversa iniciada pelos professores sobre o sentido que atribuem à escola, transcorre pela perspectiva de uma educação escolar formativa, por assim ser, contribue para o ensino e a aprendizagem mediante princípios norteados por uma atitude crítica e reflexiva acerca do ato de ensinar e aprender. Entendemos as percepções apresentadas pelos entrevistados e corroboramos que a escola se configure como espaço-tempo com implicações direcionadas à aprendizagem, tanto de conhecimentos e prática sistematizados quanto dos valores para a vida coletiva e social.

O sentido revelado à escola, pelos entrevistados, converge para relações sociais na escola que transcendem a materialidade do espaço escolar (FREIRE, 1996). Apreendemos, com base nisso, que educar é o objetivo elementar da escola e envolve para além dos aspectos técnicos pedagógicos, a dimensão afetiva e social dos envolvidos no processo educativo: gente.

Acerca dos valores, sentidos revelados nos discursos dos professores, vale destacar, que não se trata de um papel básico da escola, todavia, ela assume responsabilidade nessa perspectiva, pela formação de cidadãos para a sociedade. Então, se a responsabilidade da escola envolve a preparação da criança e do adolescente para a vida pessoal e profissional, é intrínseca a atenção na formação de valores para a vida em sociedade. Essa compreensão é coerente com o antevisto nas legislações que regulam as instituições escolares, quando apontam os compromissos assumidos entre sociedade, escola e família para o integral desenvolvimento do indivíduo.

Consideramos presente nas narrativas dos informantes, discursos que traduzem, de forma significativa, um pensamento sobre a escola, enquanto espaço-tempo possível e necessário para desenvolver um ambiente plural. Nele a produção se dá por meio das trocas e das experiências culturais continuamente. Entende-se a escola como lugar em que a história acontece e serve, portanto, como objeto de ações e interações sociais, políticas e culturais. "Experiências que são apreendidas, distinguidas, colocadas em relevo [...] agora se tornam objetos da atenção enquanto experiências 
constituídas. [...] Somente uma experiência passada pode ser chamada de significativa" (SCHUTZ, 2012, p. 75-76).

\section{CONSIDERAÇÕES FINAIS}

Cientes da conjuntura política atual, das condições materiais para o trabalho docente, do lugar da valorização e do reconhecimento profissional no contexto social e econômico, além de conscientes da função social desse ofício, fica entendido por meio deste trabalho que o(as) professor(as) acreditam que todo indivíduo aprende, por isso, seguem atentos à sua prática pedagógica. Eles promovem intencionalmente ações que contribuem para o desenvolvimento humano e para a transformação social. Também reconhecem que labutam com gente e com o conhecimento em relação com um mundo real, diverso e subjetivo.

Ao longo da investigação, apreendemos que os sentidos atribuídos envolvem a motivação inicial para a trajetória profissional, antes mesmo de dar início à carreira docente, por isso, essa compreensão requer considerar as experiências no percurso e sua constituição no contexto da formação, por meio das relações intersubjetivas.

Isso nos leva a entender que, no decorrer das experiências vividas, há um caminho de aprendizados que escoltam a formação do indivíduo, seja na esfera acadêmica, pessoal, no exercício profissional, na prática pedagógica desenvolvida na relação com os estudantes, com os colegas de trabalho, ou mesmo com a equipe pedagógica.

Diante dos aspectos apresentados no texto, entendemos como a motivação na formação e as experiências de vida influenciam no modo do professor pensar a prática pedagógica que desenvolve e acredita. Essa motivação também interfere na maneira como caracteriza os significados em torno da educação, do currículo e da escola.

Fica apreendido, por meio desta pesquisa, a inquietação no discurso dos docentes no que diz respeito à formação do estudante e, nomeadamente, ao processo de ensino e aprendizagem, haja vista que a escola, campo da pesquisa, recebe adolescentes de bairros marginalizados. 
Esses fatores traduzem a amplitude de sentidos no espaço-tempo escolar, como a singularidade de cada professor(a) informante desta pesquisa.

O sentido de educação que reverbera nas falas dos entrevistados parte da educação escolar como formação, instrução e possibilidade de transformação. De tal modo, a educação escolar é vista como o alicerce dessa formação que vai cooperar com uma formação para a vida, logo, um processo constituído por meio das relações entre escola, família e outros contextos do mundo da vida. A escola, nessa perspectiva, começa a ser vista como um ambiente para partilhar conhecimento, onde há interação entre o aprendizado e o ensino.

Trata-se, assim, da ciência de um espaço coletivo para a troca de conhecimento e que deveria contar com a participação da comunidade escolar para assegurar o direito de aprender ao estudante. A escola, nesse caso, é apresentada com uma disposição organizativa flexível e necessária, um sistema aberto que pode refletir sobre suas ações, além de ser capaz de refazer caminhos.

Na análise dos discursos, entendemos que conhecimento escolar está relacionado ao currículo prescrito, por conseguinte, o currículo é guiado e estruturado pela legislação educacional vigente para o Ensino Fundamental Anos Finais. Todavia, há entre o(as) professor(as) um cuidado atento referente à transmissão do conhecimento e à maneira como trabalha o currículo, uma vez que destacam, em suas falas, a importância da contextualização com a realidade, ou mesmo da aplicabilidade desse conhecimento na vida social, nota-se assim, a importância de se perceber o currículo de maneira real e dinâmica, que carece de adequações, ajustes, inferências e reorganizações mediante o processo de ensino.

Por intermédio dos discursos, compreendemos que, embora tenham atribuído sentidos à educação, à escola e ao currículo, está presente a singularidade e individualidade de cada docente em sua prática pedagógica, o que evidencia uma relação entre o fazer e a identidade docente. Entender o que representam estas experiências vivenciadas pelos professores, por meio do olhar reflexivo, permite-nos abarcar o 
conhecimento que o sujeito constitui em sua intersubjetividade, o que se dá quando há interação com o outro.

Consideramos relevante acadêmica e socialmente investigar os sentidos que o(as) professor(as) atribuem à prática pedagógica, especialmente por compreender que tais sentidos se estruturam e estão atravessados pelas experiências do professor no mundo da vida. Nesse sentido, a prática pedagógica passa a ser compreendida para além dos elementos vinculados à formação docente ou à prática social que exerce por meio dela.

\section{REFERÊNCIAS}

AMADO, J.(org.). Manual de investigação qualitativa em educação. $3^{a}$. ed. Coimbra: Imprensa da Universidade de Coimbra, 2017. APPLE, M. Ideologia e currículo. 3a . ed. Porto Alegre: Artmed, [1979] 2006.

BRASIL. EDU Fundação Lemann. Censo. Taxas de Rendimento (2018): Reprovação ou Abandono. QEdu, 2018. Disponível em: https://www.qedu.org.br/brasil/taxas-rendimento. Acesso em: 07 de nov. de 2020.

CÉZAR, I. R. F.; CRUSOÉ, N. M. de C. A abordagem fenomenológica shutziana e sua aplicação na compreensão da prática pedagógica dos anos finais do ensino fundamental. Práxis Educacional, [S.I.], v. 17, n. 48, p. 1-19, 2021. DOI: 10.22481/praxisedu.v17i48.9238. Disponível em: https://periodicos2.uesb.br/index.php/praxis/article/view/9238. Acesso em: 17 de set. de 2021 .

CRUSOÉ, N. M. de C. C.; SANTOS, E. M. Fenomenologia sociológica de Alfred Schutz: contribuições para a investigação qualitativa em prática educativa. Rev. Tempos Espaços Educ. v.13, n. 32, e-13274, jan./dez., 2020.

CRUSOÉ, N. M. de C. Prática pedagógica interdisciplinar na escola: sentidos atribuídos pelas professoras. $1^{a}$. ed. Curitiba, PR: CRV, 2014.

FREIRE, P. Pedagogia da Autonomia: saberes necessários à pratica educativa. São Paulo: Paz e terra, 1996.

INEP. Instituto Nacional de Estudos e Pesquisas Educacionais Anísio Teixeira. MEC. Sinopse Estatística da Educação Básica 2017. [online]. Brasília: Inep, 2019. Disponível em: http://portal.inep.gov.br/sinopses-estatísticas-daeducação-basica. Acesso em: 07 de nov. de 2020. 
LIBÂNEO, J. C. Didática e práticas de ensino e a abordagem da diversidade sociocultural na escola. XVII Endipe. Fortaleza, 2014.

LOPES, A. C.; MACEDO, E. M. Teorias de Currículo. Apoio Faperj. São Paulo: Cortez, 2011.

MINAYO, M. C. de S. O desafio do conhecimento: Pesquisa Qualitativa em Saúde. (12a edição). São Paulo: Hucitec-Abrasco, 2010.

SACRISTÁN, J. G. O currículo: uma reflexão sobre a prática. $3^{a}$. ed. Porto Alegre: ArtMed, 2000.

SHULTZ, A. Sobre a fenomenologia e relações sociais. Edição e organização: Helmut T. R. Wagner. Tradução: Raquel Weiss. Petrópolis, RJ: Vozes, 2012.

TARDIF, M. Saberes docentes e formação profissional. Petrópolis: Vozes, 2002.

TOLEDO, E. de L.; COUTINHO, H. do N. Licenciatura: escolha ou falta de opção. Revista Exitus, 10(1), 2020. e020029. https://doi.org/10.24065/22379460.2020v10nOID1253.

UNICEF. Trajetórias do sucesso escolar. 2933307 - Vitória da Conquista: Redes de Ensino, 2018. Disponível em:

https://trajetoriaescolar.org.br/painel/municipio/2933307/2018/. Acesso em: Março de 2020.

VOGEL, A. V. Bananeira não dá pêra: e outras crônicas sobre educação.

Curitiba: Editora Piá, 2020.

Recebido em: 01 de outubro de 2021. Aprovado em: 05 de novembro de 2021. Publicado em: 17 de dezembro de 2021. 